\title{
Problems faced by female teachers at primary level in Khyber Pakhtunkhwa Pakistan
}

\author{
Sayyed Farooq Shah", Safdar Rehman Ghazi, Irfan Ullah, Rahmat Ullah shah \\ Institute of Education \& Research, University of Science \& Technology, Bannu, Pakistan \\ Email address: \\ farooqshah582@gmail.com (S. F. Shah),drsrghazi@yahoo.com (S. R. Ghazi), thescholaredun@yahoo.com (I. Ullah), \\ rahmat123@yahoo.com (R. U. shah)
}

\section{To cite this article:}

Sayyed Farooq Shah, Safdar Rehman Ghazi, Irfan Ullah, Rahmat Ullah shah. Problems Faced by Female Teachers at Primary Level in Khyber Pakhtunkhwa Pakistan. International Journal of Elementary Education. Vol. 3, No. 2, 2014, pp. 34-40.

doi: 10.11648/j.ijeedu.20140302.13

\begin{abstract}
The schooling structure of Pakistan, in terms of quality education and knowledge having the lowest ranking position in the globe. Several reasons can be held to blame for this state of affairs.i.e the quality of learning and competency level of both students and teachers in Pakistan is among the poorest in the region. One of the reasons is the low level of educational qualifications required to become a primary school teacher. Another is the quality of teacher certification programs, which suffers from the lack of adequately trained trainers, little emphasis on teaching practice and non-existence of proper support/monitoring system for teachers. Teacher and its role is one of these rudiments. Because teacher is key part of the schooling and learning progression, which faces diverse tribulations owing to which they cannot play their roles efficiently in the education process. This ongoing text is based on a systematic analysis of the on hand text, decisively analyses the tribulations faced by female primary school teachers in the Khyber-Pakhtunkhwa Pakistan. Conclusion of this present on hand study reveals that teachers are not as much should be provoked towards teaching occupation, due to their appointments, transfers, place of posting and individual promotions, rapid rate of bribery and political affiliations and interference relatively than on merit. In many cases female teachers are appointed in inaccessible areas, where they not only faced with lodging and transport tribulations. The on hand study in additional establish that female teachers are overburdened with additional classes due to lack of teaching staff in primary schools, especially on one side female teachers face huge shortage of teaching and learning resources in schools and on the other side there are smaller amount proficient development opportunities for all teachers especially for female teachers. These few mentioned factors have very much affected the procedure of schooling and education in schools. The on hand study recommends that the problems of female teachers could be resolved to somehow by establishing an atmosphere of faith and intensification the system of answerability, on condition that schooling and education assets to female primary schools, providing ongoing proficient advancement opportunities and incentives to those devoted female teachers, making transparent appointments system and making clear promotions procedure just on merit, making arrangement for providing enough teaching and non teaching staff to female primary schools and rooting out the evil of political interference and involvement.
\end{abstract}

Keywords: Education, Problems of Female Primary Teachers, Possible Solutions, Quality of Schooling and Learning

\section{Introduction}

It is tremendously imperative that girls have the same admittance to education in all disciplines. When girls are not educated, the foremost part of human resource is shattered. Their uneducated residents have little economic value inside and outside the home. Education is development and a key to success. Existing scientific and technological development can only be attributed to education (Bregman and Muhammad, 1998). The standard of education of a country intertwined and determines its position among other nations of the world. In this regard countries with high achievements in the fields of education and research lead the world. Education influences living standard as it turns the population of a country into useful human capital and works as an agent of positive change (Hoodbhoy, 1998). However, it is worth noting that teacher(s), as builders of the nation, holds a pivotal role in the process of education. In this sense the quality and standards of education are strongly associated with the 
quality and effectiveness of its teachers. Unfortunately in Pakistan very little attention has been paid to the education sector in general and the recruitment of quality teachers in particular. Resultantly, Pakistan has one of the lowest literacy rate and quality educations (Farooq, 1990). This study attempts to examine the problems faced by school teachers such as, academic, recruitment and promotion procedure, administrative and power structure, financial, training, curriculum, parental relations, and examination in Khyber-Pakhtunkhwa province of Pakistan.

\section{Education in Pakistan: A Extremely Ignored and Forgotten Segment}

Education in Pakistan, from the extremely start, has in no way remained a main concern for equally the military and civil elected governments. A dreadfully restricted sum of the GDP (little above 2\%) has been billed to the education sector in Pakistan. As a result, Pakistan has the lowest literacy rate (Pakistan ranks 113th among 120 countries regarding literacy rate, which is projected to reach 60 percent till 2015 from the existing 55 percent and poor quality education compared to its neighboring countries, especially India i.e (India's 71 percent, while Bangladesh was estimated to have 61 percent literacy rate The education system of Pakistan, apart from the government negligence, eroded because of multilingualism, inconsistency and experimentation of the education policies and its stratified nature. Apparently the ramifications of this can be seen in the poor economic, political and social development of Pakistan. The system of government schooling does not respond satisfactorily to the needs of the society, because, it is considered to be poorly managed, poorly financed and poorly assessed. There are doubts upon the quality of schooling and learning in government schools from all quarters of the society (Government of Punjab, 2002). The circumstance does not look like to be improving. Many attempts were made by consecutive governments to lift up the quality of schooling and education to acceptable national and international standards. But it did not bring any encouraging results. This frightening situation indicated that the system of education is going towards a big collapse and failures (Ashraf, 1983). The system of education faces different problems. One of the critical factors which have affected the system is teacher. Although, research shows that teachers are the key to success of any education system. However, studies show that in Pakistan the problems of school teachers have multiplied with the passage of time which has exacerbated the largely system of education (Government of Pakistan, 1998). There is feeling of estrangement among the teaching community. Teaching profession is considering the mainly poorly paid, less profitable and unappealing profession (British Council, 1988). Being a terminal stage, it is the most crucial level of education of a child. Problems faced by teachers at this level dangerously affect the overall process of schooling and learning. As very small research in this area has been done, therefore, this ongoing study was launched to spot out the major problems faced by female government primary school teachers in Khyber-Pakhtunkhwa, Pakistan and to suggest possible solutions to these problems. In the underlines we shall discuss the problems faced by female government primary school teachers.

\section{Problems of Government Female Primary School Teachers in Khyber-Pakhtunkhwa, Pakistan}

\subsection{Problems as a Result of Prevailing Society}

We are living in a society where every one of us like their daughters/women to be treated and taught by female nurse and teacher but intensively hate and dislike our women/girls/female to part in education or services hence the matter seems quite ambiguous

\subsection{Problems as a Result of Economic Conditions}

Owing to getting a smaller amount of financial support, the side of education system has remained the most under paid and poor in performance especially in female. This fact has rendered the education sector as the most unattractive profession in the country. Teacher community, being the most finically poor in society, often look for other sources of earning such as going abroad for working and run their own businesses at the cost of their professional integrity (Zafar, 2003). In this regard teachers are less motivated towards and take least interest in their school duties. In many cases teachers get salaries without attending the schools because of their businesses. This has retarded the process of quality teaching and learning in schools (Shahzadi and Perveen, 2002).

\subsection{Problems as a Result of Household Activities}

Sometimes due to huge family and laborious work the female teachers become so busy and involved that she does not pay full attention to school and teaching profession although govt has done much to uplift the miser and pity conditions of teachers but still much efforts and determination is required to overcome this problem (Riasat at,el,2005).

\subsection{Problems as a Result of Political Interference}

Education system of Pakistan now a day's very highly politicized. In common cases teachers are inducted on the basis of their political affiliations rather than on merit, who often serve as political workers instead of performing their professional duties. if a teacher has no political affiliation to any political party then it is very hard to maintain his present place and position Similarly due to political tie in the education sector, over and over again the established process of selection is despoiled. These politically chosen 
ineffectual teachers become a permanent burden on the economy and a cause of the fall down of the educational system (Shah, 2003). Further, their illegal promotions and politics in the schools get in the way the educational progress in terms of quality schooling and learning as well as expose the spirit of dexterity among the teaching society. It is also important to point out here that often teachers who do not pay attention to the dictations of the political actors are harshly punished in social or financial terms and sometimes transferred to far-flung areas especially hard for female teachers. This lack of professional freedom of female teachers has deficiently exaggerated the degree of success of their duties. They work with slightest curiosity and motivation (Saleem, 2002).

\subsection{Problem as a Result of Social Recognition}

According to Rehman (2002) teaching is considered the most important and critical position in the entire education systems well as a deferential professions in all societies of the world. It is considered one of the main pillars of a society (Adams, 1998). In some countries teaching is taken as the most honorable and lucrative profession. In developed nations teachers are adored and occupy a reverential social position in society. However, in Pakistan teachers, particularly school teachers, in theory are exalted but the reality is the other way round. In Pakistan, teaching profession does not enjoy a great social status in the society. Teaching is considered the most underpaid and less attractive profession as compared to other professions like medical or engineering and so on. Malik (1991) discovered that in Pakistan the social status of teachers is accepted only at the extent of Holy Scripture. For example, ideologically teaching is deemed as the prophetic profession and teachers as the promoters of prophetic job. However, in practice this does not exist. Teachers stand at the last edge of the social ladder in society. This phenomenon has decreased the self-esteem of teachers. In these conditions the profession of teaching is the most little attractive field of service for the youth. Normally teaching is the last option in the priority list of different professions.

\subsection{Problems as a Result of Lodging and Amenities}

Government does not give any housing lodging to female primary school teachers. Female Teachers posted in farflung areas or outstations where they had to face the problem of lodging and protection. Especially female Teachers cannot have enough money to rent out houses on the money which is given to them and by a hair's breadth make their living. Due to non-availability of executive housing female teachers make extended absentees and are not capable to carry out their duties with complete concentration and happiness (Government of Punjab, 2004; Hussain, 2001).Accommodation is a major irritant in the sound family life of teachers. Due to absence of official accommodation, majority of the time of a teacher is spent in finding an accommodation. It has been observed that when finally a teacher finds an accommodation his next transfer is almost due. Due to which teacher greatly disturbed. It has been experimental that female teachers who are posted in far-off areas are more worried in return transfer to their close stations from the time of transfer to the school. This practice depressingly affects the recital of the female teachers which leads to commotion and mental agonies.

\subsection{Problems as a Result of Frequent Transfers}

Female Teachers in Pakistani schools are constantly at the sweet will of education officers and school administration. The transfers are usually made on the basis of favoritism and nepotism. Due to this practice most of the teachers remain in high mental agony, disturbance and pressures (Khan, 1980). Often transfers to remote areas are made to teach a lesson to the teachers who are either disobedient or have affiliation with opposing political party. Sometimes the newly transferred teachers do not find enough time to get adjusted to the new environment. The practice of frequent transfer of teachers creates not only disturbances for the female teachers itself but for their families, children but also affects the quality of schooling and learning in the girls schools (Farooq, 1993).

\subsection{Problems as a Result of Professional Development}

The success of any educational system depends on good and well-resourced teachers. Teachers cannot be replaced with any other kind of instructional material .Teaching is a profession which needs frequent updating. In this view female teachers should be alert of the new changes happening in the humanity and around the world. Likewise they need to be continuously abreast with latest theories, research and other addition to the pool of knowledge. It has been observed that female teachers who are not competently sound and upgraded are not able to handle with the diverse changes and variations in the society, country and the humanity at large. On the contrary female teachers who obtain latest knowledge and develop their skills can effectively manage the process of teaching and learning. They teach and learn better (Farooq, 1990).

Effective female teachers require being successful learners as well. Nevertheless, the professional development of female teachers has not been given any appropriate concentration in Pakistan. Resultantly, female teachers are establishing feeble in solving students' academic and societal harms. Additional, it is experimental that students graduating from the (government) schools have deprived communication skills and find it hard to contract with problems of life. As students in Pakistanis schools remember the concepts for examination rationale, they are short of investigative, deep and decisive skills like their teachers. This circumstance has exaggerated the generally degree of quality of education in the country (British Council, 1988). 


\subsection{Problems as a Result of School Culture}

Relationship and coordination amongst female teachers and with their executive staff is vital for creating an atmosphere of reliance and efficacy. Be short of friendly relations affects the process of effective schooling and learning. The negative effects of politics in Pakistani schools have extremely exaggerated the cooperative guts amongst teaching community. In some cases principals or head teachers give favors to only those female teachers who admit their dictations without any hesitation and appraisal. Teachers who question them or ask for more support are deliberately overlooked and ignored. This perform has given birth to suspect and de-motivates some of the teachers who hate smooth talk. Normally school principals run schools like a kingdom, least encourage coordination among the staff, and have lack of vision (Government of Pakistan, 2001). In schools there is a culture of backbiting, slurring, tormenting, pleasing and leg pulling among the teaching community, often leads to skirmishes. The final effects of this fall on the students and quality of education. On the whole, due to this the procedure of quality of education in the schools is deeply affected (Khalid, 1998).

\subsection{Problems as a Result of Community Involvement}

Teachers are not given due respect in their society that is why teaching profession is constantly losing its respect and qualified people join other professions. Only people having low caliber and ability join teaching profession.Schools are community in miniature. Teachers are important change agents, mentors and academic leaders of the society. In Pakistani, government, schools the concept of parental participation is very poor. Teachers normally face negative remarks form the parents' side as any (ill) performance of the students is related to the performance of the teachers only (Muhammad, 2002). Students who fail or show low marks in the examination, the teachers are held responsible for this without realizing that the performance of the students is associated with the role of school administration, parents and teachers. It is injustice to only hold teachers responsible for the bad results of the students in examination and so on. There is lack of awareness on the part of the parents and community that parents and community is equal stakeholder in the development of the student (Illahi, 1986).

\subsection{Problem as a Result of Overloaded Classes}

According to Kahlid (1998) the out of reach working circumstances in Pakistani schools have added to teacher suffer exhaustion. There are no measures of work in some schools either due to the ignorance of the administration or laps on the part of female teachers to find out the procedure of work. In the mass of schools, mostly in far-flung areas, there is being short of female teaching staff. This overburdens other teachers in the schools. In view of Saleem (2002) this situation has increased more pressures on the teachers who become prone to physical discomforts. In this situation the teachers try to cover the syllabus at the cost of the quality in teaching and learning. Teachers cannot pay individual attention to many students which is a great psychological and social need of students.

\subsection{The Problems as a Result of Physical and Learning Resources}

The lack of teaching and learning aids in schools creates difficulties in the teaching process especially for female. Some girls schools even do not have basic aids such as black boards, attendance registers, offices, libraries, laboratories and up-to-date books. Even the majority of girl's schools have lack of classrooms. In majority of girls schools there are no proper playgrounds for the physical development of students and teachers (Qureshi, 2002). This has created more monstrous problems for female teachers as they cannot provide the students wider opportunities for learning and development. Since teachers are expected to cover courses well in time, however, in the given conditions they fail to create meaningful learning environment in schools (Hussain, 2001).

\subsection{Problems as a Result of Supervision}

Rasheed, (2004) has found that there is a poor concept of supervision in Pakistani schools. The process of supervision is filled with bureaucratic underpinnings. In essence the purpose of supervision is to develop and improve the performance of teachers and students. Conversely, in Pakistan the process of supervision is characterized with the notion of inspection. Supervisors create an environment of fear during the process of supervision (Mohanty, 990). The supervisors behave like kings and treat the teachers like salves and inferiors.

This trend has created mistrust as well as affected the spirit of cooperation among the teachers on one hand and teachers and administration on the other. The supervisors instead of providing constructive feedback give orders to the teachers and hence no improvement takes place (Khan, 1998).

\subsection{Problems as a Result of Coordination and Cooperation}

The system of education in Pakistan lacks a mechanism of coordination. This problem has taken rots due to weak communication between the policy makers, staff, parents and the community. The state of poor coordination in the system has promoted misunderstandings between the stakeholders (Farooq, 1993). Teachers remain at the receiving end in all areas, e.g., in making of curriculum or any other education policy. Teachers participate only in the implementation not in the development part. This ends up in the creation of a culture of blame-game. There is even lack of coordination between teachers and principals (Zafar, 2003). This lack of coordination in view of Ashraf, (1983) has stopped discussion on different problems in schools as 
well as that of teachers. In this regard no effective measures can be taken to resolve vital issues at the school level.

\subsection{Problems as a Result of Prevailing Curriculum}

Curriculum development in Pakistan is a centralized activity. Curriculum is developed and schools are supposed to implement it without any manipulation. In this regard teachers' role is that of implementer. They cannot contribute towards the process of curriculum development and evaluation neither they are provided with refresher courses to be in line with the updated syllabi (Hoodbhoy, 1998). This tradition has left the teachers ignorant of many aspects of the curriculum which ultimately affects not only their own performance but also the process of teaching and learning in schools. In many cases teachers are not aware of the aims or goals of the curriculum for certain levels. This creates gaps between understating of the curriculum and its effective implementation. However, in developed countries teachers are invited to participate in the process of curriculum design and development. Their inputs are considered vital for the right direction of the education system (Government of Pakistan, 2001).

\subsection{Problems as a Result of Textbooks}

Textbooks are a very important aspect of teaching and learning process (Farooq, 1993). Textbook development is highly specialized area in curriculum development. Female teachers in Pakistani girls' schools face problem of instruction due to non-availability of quality textbooks. There is a culture of multilingualism and medium of instructions in schools. This creates an environment of uncertainty, difficulty, fatigue and lack of understating both on the part of female teachers and students. Moreover, there is lack of training of female teachers on how to smooth the progress of or explain concepts from different textbooks (Hussain, 2001). This lack of orientation has created confusion among female teachers which reflects in their poor performances. Due to this female teachers as well as students are least interested in the process of learning. As teachers are expected to cover the syllabus before examination by all means, they, in order to overthrow the burden from their head and due to lack of understanding, resort to only reading and preaching the books without taking into account the vital aspects of schooling and learning such as development of various skills (communication, analysis, reflection) of students and enhancing their knowledge in an effective way (Khalid, 1998).

\subsection{Problems as a Result of Delivery/Pregnancy}

All married woman has the common problems of pregnancy/delivery which female teachers face repeatedly during the entire service i.e on one side she has to performed his official duty and on the other side she faces a lot of complication and hurdles during this period, which is quite alarming one.

\subsection{Problems as a Result of Male Clerkal and Class-4 Staff}

This is another alarming issue in most of our female schools. Firstly there is hardly clerkal staff present in female schools. If it is present somehow in their schools it is in the shape of men and every ones know that female feel hesitance dealing with men in the Islamic society, similarly class-4 staff seldom present in female schools if present so it is in the form of men which very hard for female teachers to cope with men rather than female class- 4

\section{Findings and Conclusions of the Study}

The purpose of this study was to explore the problems faced by female teachers at primary school level in KhyberPakhtunkhwa through a critical review of literature. The study fulfilled that overall system of education in Pakistan is affected by versatile issues, however, female teacher occupy a central role in this state of affairs. In this regard it was noted that there is lack of motivation among female teachers towards teaching profession due to smaller amount facilities in this career. Female teachers get fewer salaries as compared to other professionals in the country. Moreover, female teachers are frequently transferred from one place to another on the basis of preferential treatment and bias, thereby making them tormented and gloomy. The study also concluded that there are no facilities of accommodation for female teachers posted in far-flung or outstations. Due to political intervention in the procedure of assortment, under qualified female teachers are appointed who cannot effectively manage the process of schooling and learning in schools.

The study also concluded that female teachers are overburdened with extra classes due to shortage of female staff in the girls' schools. Be short of resources in girls schools render the female teachers helpless while they need different aids for schooling and learning. There are no training facilities available to professionally update the female teachers to improve their teaching skills. The on hand study further explored that in girls schools, head master in most cases create master servant environment which makes the female teachers feel estranged from the system. Political groupings in female schools have defectively affected the bond between teachers and head teachers. This has also grimly exaggerated the procedure of quality of education in especially in girls' schools.

\section{Recommendations of the Study}

Keeping in mind the findings of this ongoing study it is recommended that the problems of female teachers in Khyber-Pakhtunkhwa in particular and Pakistan in general should be tackled down through the following ways:

1. Atmosphere of reliance and intensification should be 
created, the system of liability in the school systems, the function and recital of the female teachers should be enhanced.

2. To maintain the attention of female teachers in the teaching occupation government should boost conveniences for female teachers, which will boost their enthusiasm plane. This will have a optimistic bang upon the by and large schooling and learning process.

3. For the enhancement of quality of schooling and learning the institutions are desirable to be provided with different schooling and learning assets. It will pick up the level of excellence of learning and schooling. For this reason additional cremation should be provided to girls schools to be used in purchasing of paraphernalia for schooling and learning aids.

4. Schools are considered necessary to be entirely at no cost from bribery and political affairs. For this reason, it is required to be ensured that political intervention should be minimized fairly out rooted from schools so that an environment of professionalism and trust is built.

5. Clean assortment on the basis of prerequisite ensures the selection of qualified people for teaching. Experienced people develop systems. Hence, it is suggested that at some point in the process of selection or appointments of female teachers merit should be strictly keep in mind.

6. The earth is full up with new-fangled changes and developments. Teachers manufacture professionals for the upcoming. Consequently, the female teachers necessitate being fully alongside each other with new information, study and most recent information in order to successfully coach and educate the kids for their upcoming roles. For this purpose, female teachers necessarily needed training on frequent basis. The teachers may be provided opportunities to participate in ongoing professional development programs to enhance teaching skills of teachers.

7. Female Teachers are the basic assets in the process of education. Female Teachers' involvement in the curriculum development will boost the degree of excellence of education in schools. For this reason, it is suggested that female teachers should be equally provided opportunities to involve yourself in the process of curriculum development.

8. In order to keep hold of the level of interest among female teachers, the allotment of classes should be simplified in schools by the principals or the higher establishment. To overcome this dilemma more female teachers should be provided to schools so that female teachers are not overburdened with additional classes and their energies are not pooped.

9. In order to work out the dilemma of course book, female teachers should be advised to transmit the knowledge to on daily basis experiences of their students. As a replacement for of teaching the book, female teachers should be advised to teach thoughts by using other sources such as the media, journals and so on. For this reason, school establishment should participate a imperative task. In this way female teachers will be able to handle with the uniformity of textbooks.
10. For successful schools efficient system of synchronization is necessary. Female Teachers should be communicated appropriately about the different developments taking place in the system of education like policies, programs and etc. In this way, the female teachers will develop a sagacity of care and feel to a team player rather than a fixing part in a system. This will boost their confidence and they will contribute in the process of schooling and learning ardently.

11. since for smooth running and anticipation of the female teachers both the clerklal as well as clss-4 staff should may necessarily be female rather than men ,so that female teachers can exchange their views and problems freely to own non teaching staff and himself keep in teaching etc activities.

\section{References}

[1] Ashraf, M. (1983). "An Evaluation of Existing Supervision Practices in Pakistan.” p. 120-126). Lahore:

[2] Bregman, J. \& Muhammad, N. (1998). "Primary and Secondary Education Structural Issues". (pp.23-31) Islamabad: Jan Publications

[3] British Council (The) (1988). "Survey on Teacher Training in Pakistan." Islamabad: The British Council Educational Contracts Department Overseas development Authority.

[4] Farooq, R.A (1993). "Education system of Pakistan: Issues and Problems". Asia society for promotion of Innovation and Reforms in Education. Islamabad: Pakistan pp.10-20

[5] Farooq, R. A. (1990). "A Survey Study of Teacher Training in Pakistan. Academy of Educational Planning and Management", Ministry of Education. Islamabad

[6] Government of Pakistan (GoP) (1998). "National Education Policy 1998-2010.” Islamabad:

[7] Ministry of Education Government of Punjab (2002). "Examination and Continuous Assessment". Lahore:Directorate of Staff Development

[8] Government of Pakistan (2001). "Technical group Meeting on Devolution and Decentralization, Implementation for the Sducation Sector." Ministry of Education, Islamabad, Pakistan

[9] Government of Punjab. (2004). "Standard Manual, Elementary, Secondary and Higher

[10] Secondary Schools”. Education Department, Punjab, Lahore, Pakistan, pp. 10

[11] Hussain, S.A. (2001). "Education in Pakistan". Allama Iqbal Open University. Islamabad, Pakistan pp.1-12

[12] Hoodbhoy, P. (1998). "Education and the State: Fifty Years of Pakistan". Karachi: Oxford UniversityPress.

[13] Hayes, L.D. (1987). "The Crises of Education in Pakistan." Lahore: Vanguard Books

[14] Illahi, M.A (1986). "The Role of the Heads of Secondary Schools." (Unpublished thesis) 
[15] Allama Iqbal Open University, Islamabad. Pakistan, pp. 1222

[16] Khalid, T. (1998). "Education: An Introduction to Educational Philosophy and History".

[17] National Book Foundation, Islamabad, Pakistan pp.22.35

[18] Khan, M.A. (1998). “An Appraisal of Supervisory Practices in the Schools of District

[19] Attock". (Unpublished thesis), University of Arid Agriculture, Rawalpindi, Pakistan. pp.33-45

[20] Khan, M.S (1980). "Educational Administration," Ashish Publishing House, H-12, Rajouri Garden, New Delhi: India.pp.23-34

[21] Khan, N.I (1992). Evaluation of the Administrative structure of high (secondary) schools in Punjab. (Unpublished thesis). The University of Punjab, Lahore, Pakistan. pp.11-22

[22] Malik, S.R (1991). "The System of Education in Pakistan". National Book Foundation, Islamabad, Pakistan. pp.13-20

[23] Mohanty, B. (1990). "School Administration and Supervision". Deep and Deep Publication. Rajouri Garden, New Delhi, India. pp.20-33

[24] Muhammad, M. (2002). "Decentralization of Education
System in Sind: A Critical Review. Ministry of Education," Islamabad, Pakistan. pp.10-18

[25] Qureshi, S. (2002). "Decentralization to District Level." Ministry of Education, Islamabad, Pakistan. pp.31-40

[26] Rasheed, M. (2004). "Educational Administration and Supervision". Allama Iqbal Open University, Islamabad, Pakistan. pp.145-166

[27] Rehman, J.U (2002). "Devolution and Decentralization: Identification of Progress in Implementation in Education". Ministry of Education. pp. 233-240

[28] Saleem, M. (2002). "Facts and figures". Agha Khan Gee Printers, Islamabad, Pakistan. pp.07-10

[29] Shah, D. (2003). "Decentralization in the Education System of Pakistan: Policies and Strategies". Academy of educational Planning Management. Islamabad, Pakistan. pp.18-23

[30] Shahzadi, R \& Perveen, K (2002). "An Evaluation of New Educational Structure". (Unpublished thesis). The University of Punjab, Lahore, Pakistan. pp. 65-68

[31] Zafar, M. (2003). "Fiscal Devolution in Education". Case study Reflecting Initial Responses. Ministry of Education, Islamabad, Pakistan. pp.34-41 